\title{
CYP17A1 inhibitor abiraterone, an anti-prostate cancer drug, also inhibits the 21-hydroxylase activity of CYP21A2
}

Jana Malikova ${ }^{1,2, \#}$, Simone Brixius-Anderko ${ }^{3, ~ I I, ~ \#, ~ S a m e e r ~ S ~ U d h a n e ~}{ }^{1,2, \Psi}$, Shaheena Parween $^{1,2}$, Bernhard Dick ${ }^{4}$, Rita Bernhardt ${ }^{3}$ and Amit V. Pandey ${ }^{1,2, *}$

${ }^{1}$ Pediatric Endocrinology, Diabetology and Metabolism, University Children's Hospital, Inselspital, Bern, Switzerland

${ }^{2}$ Department for BioMedical Research, University of Bern, Bern, Switzerland

${ }^{3}$ Department of Biochemistry, Faculty of Technical and Natural Sciences, Saarland University, 66123 Saarbrücken, Germany.

${ }^{3}$ Department of Nephrology, Hypertension and Clinical Pharmacology, University Hospital of Bern, Bern, Switzerland.

\# These authors contributed equally to this work.

${ }^{\text {II }}$ Current address: Medicinal Chemistry Department, College of Pharmacy, University of Michigan, Ann Arbor MI 48109, USA

${ }^{\Psi}$ Current address: Department of Pathology, Medical College of Wisconsin Cancer Center, Milwaukee, WI, 53226, USA.

Running title: Inhibition of CYP21A2 activity by abiraterone.

Keywords: Abiraterone, CYP21A2, CYP17A1, prostate cancer, cytochrome P450, steroidogenesis, androgens.

\section{* Address for Correspondence:}

PD Dr. Amit V Pandey

Pediatric Endocrinology, Diabetology \& Metabolism, KIKL C837, University Children's Hospital Bern, Freiburgstrasse 15, CH-3010 Bern Switzerland Tel: +41316329637

Email: amit@pandeylab.org 
42

143

44

45

46

47

\section{Abstract}

Abiraterone is an inhibitor of CYP17A1 which is used for the treatment of castration resistant prostate cancer. Abiraterone is known to inhibit several drug metabolizing cytochrome P450 enzymes including CYP1A2, CYP2D6, CYP2C8, CYP2C9, CYP2C19, CYP3A4 and CYP3A5, but its effects on steroid metabolizing P450 enzymes are not clear. In preliminary results, we had observed inhibition of CYP21A2 by $1 \mu \mathrm{M}$ abiraterone. Here we are reporting the effect of abiraterone on activities of CYP21A2 in human adrenal cells as well as with purified recombinant CYP21A2. Cells were treated with varying concentrations of abiraterone for 24 hours and CYP21A2 activity was measured using $\left[{ }^{3} \mathrm{H}\right]$ 17-hydroxyprogesterone as substrate. Whole steroid profile changes were determined by gas chromatography-mass spectrometry. Binding of abiraterone to purified CYP21A2 protein was measured spectroscopically. Computational docking was used to study the binding and interaction of abiraterone with CYP21A2. Abiraterone caused significant reduction in CYP21A2 activity in assays with cells and an inhibition of CYP21A2 activity was also observed in experiments using recombinant purified proteins. Abiraterone binds to CYP21A2 with an estimated $\mathrm{Kd}$ of $6.3 \mu \mathrm{M}$. These inhibitory effects of abiraterone are at clinically used concentrations. A loss of CYP21A2 activity in combination with reduction of CYP17A1 activities by abiraterone could result in lower cortisol levels and may require monitoring for any potential adverse effects. 
63 Androgenic steroids are required for a wide range of functions necessary for life, from the salt 64 balance by mineralocorticoids, sugar balance by glucocorticoids to the growth, reproductive

\section{Introduction} and sexual functions by sex steroids. Biosynthesis of androgens occurs in the human adrenal cortex (zona reticularis) and gonads (ovaries / testes) [1]. Enzymes for production of androgens and genes encoding these enzymes are known but the mechanism of regulation of androgen production remains unclear [2]. Steroid hormones are synthesized from cholesterol starting from conversion of cholesterol to pregnenolone by CYP11A1, a member of cytochrome P450 gene family, which is the quantitative regulator of steroidogenesis [3]. Pregnenolone can then be directed to one of three principal pathways by CYP17A1, the qualitative regulator of steroidogenesis, which catalyzes both $17 \alpha$-hydroxylase and 17,20 lyase activities $[4,5]$ (Fig. 1).

In the absence of CYP17A1, pregnenolone is converted to C21 steroids, including progesterone, corticosterone and aldosterone. In presence of the $17 \alpha$-hydroxylase activity of CYP17A1, the adrenal zona fasciculata produces C21 17 $\alpha$-hydroxy steroids including cortisol $[6,7]$. When both $17 \alpha$-hydroxylase and 17,20 lyase activities are present, the adrenal zona reticularis and gonads produce dehydroepiandrosterone (DHEA), which is the precursor of androgens and estrogens. The CYP17A1 acts as a qualitative regulator of sex steroid biosynthesis in humans [8]. CYP17A1 catalyzes two distinct reactions in the steroid pathway $[5,9,10]$; its $17 \alpha$-hydroxylase activity is essential for producing $17 \mathrm{OH}$-pregnenolone and $17 \mathrm{OH}$-progesterone precursors of cortisol, and its 17,20 lyase activity is needed for the production of the precursor of sex steroids, dehydroepiandrosterone (DHEA) . The two activities of CYP17A1 determine the type of steroid hormone synthesized in different cells and tissues; if CYP17A1 is absent, mineralocorticoids are produced, if only $17 \alpha$-hydroxylase 
activity is present, glucocorticoids are made, and if both activities are present sex steroid 88 precursors can be produced. Overproduction of androgens by specific activation of

The overproduction of steroid hormones, especially hypercortisolemia during the Cushing's syndrome, is a potentially life-threatening situation $[11,12]$. The hyperandrogenism is not a life threatening condition itself but brings many severe complications during fetal, childhood as well as adult phases of life [13]. Androgens are regulators of both, the female and male sexual differentiation $[13,14]$. The hyperandrogenism during childhood and adulthood is mainly recognized in females due to virilisation, hirsutism, oligomenorhea, infertility etc. Non-tumoral cases of hyperandrogenism are polycystic ovary syndrome, Cushing syndrome or congenital adrenal hyperplasia due to 21-hydroxylase deficiency [15-18]. The hyperandrogenism can also be the first sign of adrenocortical or ovarian tumors $[15,19]$. Overproduction of cortisol and androgens could be therapeutically influenced by drugs.

The adrenal steroidogenesis inhibitors block various steps in steroid production. Currently few drugs are approved as steroidogenesis inhibitors (Ketoconazole, Metyrapone, Etomidate, Mitatone) in the European Union or in the United States. All these drugs inhibit the CYP17A1, CYP11A1 and CYP11B1 [20]. Several other drugs like Osilodrostat (inhibitor of CYP11B and other CYP enzymes) are being studied [20-22]. In addition, new drugs such as orteronel and galeterone which are able to inhibit androgen productions in androgen depended prostate cancers are being tested [23-28]. 
112 Abiraterone was designed as a CYP17A1 inhibitor and its effect on androgen production in

the treatment of androgen depended prostate cancer was confirmed by clinical trials [29]. The U.S. Food and Drug Administration approved abiraterone acetate (Zytiga Tablets, http://www.zytiga.com)) for use in combination with prednisone for the treatment of patients with metastatic castration-resistant prostate cancer (mCRPC) who have received prior chemotherapy containing docetaxel. Abiraterone was tested in our laboratory to elucidate its effect on adrenal androgen production. The CYP17A1 inhibitors in use target both the17 $\alpha$ hydroxylase and 17,20 lyase activities and require steroid supplementation [26, 30-33]. In our previous study abiraterone inhibited both the 17 -hydroxylase and the 17,20-lyase activities of CYP17A1. Surprisingly, abiraterone also completely inhibited the 21-hydroxylase activity of CYP21A2 at the concentration for the clinical uses $(1 \mu \mathrm{M})$ [26].

Both the CYP17A1 and the CYP21A2 enzymes are localized in the endoplasmic reticulum, and catalyze important steps in the biosynthesis of steroids [8]. The CYP17A1 is the source of $17 \alpha$-hydroxylase and 17,20-lyase activities in adrenals and gonads whereas the CYP21A2 is localized only in the adrenals and catalyzes the 21-hydroxylation of progesterone/17OHP to DOC /11-deoxycortisol for the biosynthesis of mineralocorticoids and glucocorticoids. Both of these enzymes have sequence similarities and belong to the cytochrome P450 family of proteins [8] and depend on P450 oxidoreductase for redox equivalents [34]. The deficiency of CYP21A2 leads to variable symptoms depending on the amount of residual activity, ranging from the severe adrenal crisis with salt wasting symptoms to mild hyperandrogenism $[8,35$, 36].

Here, we are reporting detailed studies on the effect of abiraterone on 21-hydroxylase activity. The mode of action of abiraterone on CYP21A2 was tested using recombinant purified human 
137 CYP21A2 protein expressed in bacteria as well as in cell based assays using a human adrenal

cell line. All studies show the inhibition of 21-hydroxylase activity of CYP21A2 at clinically used concentrations of abiraterone, indicating that treatment with abiraterone should be used with caution, especially in treatment of non-cancerous hyperandrogenic disorders like PCOS.

\section{Materials and Methods}

\subsection{Materials}

Abiraterone was purchased from Selleckchem (Houston, TX, USA). Radio-labeled $\left[{ }^{3} \mathrm{H}\right]-17 \alpha-$ hydroxyprogesterone (17OH-PROG) was from American Radiolabel Chemicals Inc. (St. Louis, MO, USA). All other chemicals were purchased from Sigma Chemical company (St. Louis, MO, USA)

\subsection{Protein expression and purification}

Human CYP21A2 was recombinantly produced in E. coli strain C43(DE3) (Lucigen, Middleton, MI, USA) and purified via metal chelate (IMAC) and ion exchange chromatography as described previously. Carbon monoxide difference spectroscopy was performed to determine the enzyme quality and quantity by monitoring the absorption peaks at $450 \mathrm{~nm}$. An extinction coefficient of $91 \mathrm{mM}^{-1} * \mathrm{~cm}^{-1}$ was used for calculation of cytochrome P450 content [37]. Human NADPH- cytochrome P450 reductase (POR) was produced as recombinant protein in $E$. coli $\mathrm{C} 43$ (DE3) and purified by IMAC using established protocols [38].

\subsection{Study of Abiraterone binding to CYP21A2 by difference absorption spectroscopy}


161 Difference spectroscopy was performed with tandem cuvettes for determination of the

dissociation constant $\left(K_{\mathrm{d}}\right)$ for abiraterone according to earlier protocols. Cuvettes contained 1 $\mu \mathrm{M}$ of purified CYP21A2 in phosphate buffer (50 mM potassium phosphate $(\mathrm{pH} 7.4), 0.5 \%$ sodium cholate, $0.05 \%$ Tween 20 and $20 \%$ glycerol). Titration was performed by adding increasing amounts of abiraterone dissolved in DMSO. Difference spectra were monitored in the wavelength range of 350 to $500 \mathrm{~nm}$. The binding titrations were carried out in three different experiments. To determine the $K_{\mathrm{d}}$, the average of $\Delta \mathrm{A}$ (absorbance difference of peak-to-trough) was plotted against the concentration of abiraterone. The plots were fitted for hyperbolic regression using OriginPro 9 software (OriginLab Corp, MA, USA).

\subsection{CYP21A2 Inhibition studies with purified recombinant protein}

The inhibition studies were performed in reconstituted in vitro assays in 50 mM HEPES buffer (pH 7.4) containing 20\% glycerol and $100 \mu \mathrm{M}$ 1,2-dilauroyl-sn-glycero-3phosphocholine. Prior to use, the buffer was sonicated in a water bath for 5 minutes for the reconstitution of 1,2-dilauroyl-sn-glycero-3-phosphocholine vesicles. The concentration of human CYP21A2 in reactions was $0.1-0.3 \mu \mathrm{M}$ and equal amounts of human POR were added. Additionally, the reaction contained a NADPH regeneration system consisting of 5 mM glucose-6-phosphate, $1 \mathrm{mM} \mathrm{MgCl}_{2}$ and glucose-6-phosphate dehydrogenase. The $17 \mathrm{OH}$ PROG (substrate) was varied at a concentration of $1,2.5$ and $5 \mu \mathrm{M}$ and the abiraterone (inhibitor) was at concentrations of $0.25,0.5,1,2.5$ and $5 \mu \mathrm{M}$. The substrate concentrations were kept below saturation, but in excess over $K_{m}$ for CYP21A2. The final DMSO concentration was kept below $2 \%$. The reaction was initiated by addition of $5 \mathrm{mM}$ NADPH and incubation was performed in a water bath with shaking for $4-7$ min at $37^{\circ} \mathrm{C}$. After the incubation, reactions were stopped by addition of chloroform and steroids were extracted with 
185 chloroform. Extraction process was repeated twice, then steroids were dried by evaporation and stored at $-20^{\circ} \mathrm{C}$ for quantitative analysis by HPLC.

\subsection{Steroid analysis via RP-HPLC}

189 Steroid analysis was carried out by RP-HPLC using a Jasco reversed phase LC900 HPLC system (Jasco Inc, Easton, MD, USA) and a $4.6 \mathrm{~mm} \times 125 \mathrm{~mm}$ NucleoDur C18 Isis Reversed Phase column (Macherey-Nagel, Düren, Germany). Samples were measured within $30 \mathrm{~min}$ at $240 \mathrm{~nm}$ and a flow rate of $0.8 \mathrm{~mL} / \mathrm{min}$ with the gradient: $80 \%$ solvent A (10\% acetonitrile in water) for $13 \mathrm{~min}, 60 \%$ solvent A for $7 \mathrm{~min}, 80 \%$ solvent B (100\% acetonitrile) for $2 \mathrm{~min}$ and $80 \%$ solvent A for $8 \mathrm{~min}$.

\subsection{Inhibition of CYP21A2 activity by abiraterone in human adrenal cells}

Human adrenal carcinoma cell line (NCI-H295R) was purchased from American Type Culture Collection (ATCC, CRL-2128). The NCI-H295R cells were cultured under standard condition in DMEM/Ham's F-12 medium containing L-glutamine (GIBCO) supplemented with 5\% NU-I serum (BD biosciences), $0.1 \%$ insulin, transferrin, and selenium $(100 \mathrm{U} / \mathrm{ml}$; GIBCO), penicillin (100 U/ml, GIBCO) and streptomycin (100 $\mu \mathrm{g} / \mathrm{ml}$, GIBCO). Abiraterone was dissolved in dimethyl sulfoxide (DMSO) at stock concentrations of $200 \mu \mathrm{M}$; final concentrations used for treatment were in the range of 0.001 to $1 \mu \mathrm{M}$.

For the experiments cells were grown in twelve-well plates. Twenty-four hours after plating the cells, medium was replaced and treatment was added in normal growth medium for $24 \mathrm{~h}$. After 24 hour cells were treated with $1 \mu \mathrm{M}$ trilostane (a specific blocker of HSD3B) for 90 min before adding $\left[{ }^{3} \mathrm{H}\right]$ 17OH-PROG. $17 \mathrm{OH}-\mathrm{PROG}$ was added at two concentrations (1 and $5 \mu \mathrm{M}$ ). Control cells were treated with $0.1 \%$ (v/v) DMSO. Radiolabeled $\left[{ }^{3} \mathrm{H}\right]-17 \mathrm{OH}-$ 
PROG (50 $000 \mathrm{cpm})$ was added to the culture medium for the last $60 \mathrm{~min}$ of incubation.

Steroids were extracted from cell supernatants and separated by thin layer chromatography (TLC) on silicagel (SIL G/UV 254 ) TLC plates (Macherey-Nagel, Oensingen, Switzerland) as previously described [26, 39-42]. The steroids were visualized on a Fuji FLA-7000

PhosphoImager (Fujifilm, Dielsdorf, Switzerland) and quantified using Multi Gauge software (Fujifilm, Dielsdorf, Switzerland). The conversion of 17OH-PROG to 11-deoxycorticosterone (11DOC) showed 21-hydroxylase activity. Steroid conversion was assessed as a percentage of incorporated radioactivity into a specific steroid product in relation to total radioactivity measured for the whole sample (internal control). Data were analyzed based on MichaelisMenten enzyme kinetics [43] using the method of Dixon to determine the Ki values [44].

\subsection{Steroid profiling from cell culture}

222 Steroid metabolites from cell cultures were measured by gas chromatography-mass spectrometry (GC/MS) according to established protocols $[45,46]$. The cells were grown in $10 \mathrm{~cm}$ plates in normal growth medium for $24 \mathrm{~h}$, then medium was replaced, and cells were treated with $1 \mu \mathrm{M}$ abiraterone in medium without NU-I serum for $24 \mathrm{~h}$. After $12 \mathrm{~h}$ of treatment, $1 \mu \mathrm{M}$ pregnenolone was added. At the end of incubations supernatant was collected and concentrated samples were used for steroid analysis by GC-MS. All measurements were performed in the steroid laboratory of the Department of Nephrology, Hypertension and Clinical Pharmacology at the University Hospital of Bern, Switzerland.

\subsection{Protein structure analysis}

232 The published 3D structure of CYP21A2 waw obtained from PDB database (www.rcsb.org).

233 We performed several sequence alignments with multiple CYP21A2 protein sequences from 234 different organisms and made in-silico calculations with the programs YASARA [47] and 
235 WHATIF [48]. For all experiments, a crystal structure (PDB \# 4Y8W) of CYP21A2 was

used. Missing hydrogen atoms were added with YASARA [47] that was also used for all subsequent computations unless stated otherwise. Afterwards system was subjected to $500 \mathrm{ps}$ explicit solvent MD simulations at $310 \mathrm{~K}$, preceded by 500 steps of steepest decent and simulated annealing minimization with the AMBER03 force field and the TIP3P water model [49, 50]. All subsequent MD simulations retained these settings. The resulting minimum energy structure was used for AutoDock VINA [51] to perform docking experiments with abiraterone (orthorhombic docking was grid established around the central heme). The final poses were selected based on their docking scores and resemblance to the co-crystallized ligand in the template structure (PDB: 4Y8W). Structure models were depicted with Pymol (www.pymol.org) and rendered as ray traced images with POVRAY (www.povray.org). Ligand interactions were analysed and depicted with LIGPLOT+ (http://www.ebi.ac.uk/thornton-srv/software/LigPlus/)

\subsection{Statistical Analysis}

Statistical analysis was performed with Microsoft Excel and GraphPad Prism 6 (Graph Pad Software, Inc. San Diego, CA, USA). Statistical differences between values were calculated using the Student's t test. Quantitative data represent the mean of three independent experiments, error bars indicate the mean \pm SEM. Significance was set at $* p<0.05$ and $* * \mathrm{p}<0.01, * * * \mathrm{p}<0.001$

\section{Results}

3.1 Effect of abiraterone on steroid production by human adrenal cells. We measured the global changes in steroid production of human adrenal NCI-H295A cells upon abiraterone 
treatment (Table 1). Abiraterone lowered the production of both testosterone, and dihydrotestosterone. In addition, androsterone, etiocholanolone and their $11 \beta$-hydroxy metabolites were also lowered. Abiraterone caused major changes in cortisol metabolites with a decrease of tetrahydro deoxycorticosterone and cortisol and increase in tetrahydrocortison, $\alpha$-Cortolon, $\beta$-Cortolon, tetrahydrocortisol and $5 \alpha$-tetrahydrocortisol. Overall in addition to inhibition of CYP17A1 activities, abiraterone seems to affect a wide range of steroid metabolizing enzymes.

\subsection{Inhibition of CYP21A2 activity by abiraterone in human adrenal cells.}

269 The 21-hydroxylase activity was monitored in H295R cells treated with control (DMSO) and $2701 \mu \mathrm{M}$ abiraterone for $24 \mathrm{~h}$. CYP21A2 activities were measured by observing the conversion 271 of $\left[{ }^{3} \mathrm{H}\right]$ 17-OH-PROG (17 $\alpha$-hydroxyprogesterone) to 11-deoxycortisol using two different 272 substrate concentrations (Figure 2A). Data are presented as mean \pm SD of three independent 273 experiments for each set of substrate concentrations. We observed significantly decreased 21274 hydroxalyse activity in cells treated with abiraterone at concentrations from $0.03 \mu \mathrm{M}$ to $1 \mu \mathrm{M}$. 275 The calculated $\mathrm{IC}_{50}$ for abiraterone inhibition of CYP21A2 activity in our experiments was 25 $276 \mathrm{nM}$ at $1 \mu \mathrm{M}$ substrate concentration and $54 \mathrm{nM}$ at $5 \mu \mathrm{M}$ substrate concentration. We also 277 calculated the $K_{i}$ value for abiraterone inhibition of CYP21A2 activity by Dixon plot analysis 278 [44]. A plot of $1 / \mathrm{v}$ versus increasing abiraterone concentrations at two different substrate 279 concentrations showed a competitive inhibition / simple mixed inhibition pattern with an 280 estimated $\mathrm{K}_{\mathrm{i}}$ value of $23 \mathrm{nM}$. The strong inhibition of CYP21A2 activity at the lower end of 281 clinically used concentrations of abiraterone indicated that abiraterone is a potent inhibitor of 282 CYP21A2 activity, in addition to its effects of CYP17A1 activities. Comparison of IC $_{50}$ 283 values obtained at lower substrate concentration and the $K_{i}$ value derived from Dixon plot 
284 indicated a pattern of a simple mixed inhibition according to the Cheng-Prusoff equation [52,

53] for the mechanism of abiraterone effect of CYP21A2 activity.

\subsection{Computational docking of abiraterone into the human CYP21A2 crystal structure.}

Abiraterone was docked into the crystal structure of human CYP21A2 using Autodock VINA

(Figure 3A). Superimposition of CYP21A2 structures with either its substrate or abiraterone docked into the active site revealed similar binding poses (Figure 3B). We observed a nitrogen-iron binding pattern from the docking of abiraterone into the active site of CYP21A2 crystal structure (Figure 3C). Binding pose of abiraterone to CYP21A2 was also similar to its binding into the CYP17A1. A comparison of the CYP17A1 crystal structure in complex with abiraterone and docked abiraterone into the crystal structure of CYP21A2 revealed similar binding conformations and the distance of the imidazole nitrogen of abiraterone to the central heme iron of both, CYP21A2 and CYP17A1, was similar (3.2 $\AA$ vs $2.7 \AA$ ) (Figure 3D). Binding of abiraterone with CYP21A2 shares many similarities with its binding to CYP17A1 with many similar active site residues involved in binding for both proteins (Table 2).

\subsection{Determination of abiraterone-CYP21A2 dissociation constant by difference} spectroscopy

Since our cell culture experiments demonstrate a significant inhibition of CYP21A2 by abiraterone, which was also supported by docking studies using the crystal structure of CYP21A2, we were interested to evaluate the mechanism of this effect using in-vitro investigations with purified enzymes. To confirm the computational docking of abiraterone into the CYP21A2 structure binding of abiraterone to purified human CYP21A2 was studied. The dissociation constant for binding of abiraterone to CYP21A2 was determined by difference absorption spectroscopy (Figure 4). The formation of complex between an inhibitor 
and CYP21A2 could be determined spectroscopically by observing the type II shift in spectral changes caused by the displacement of a water molecule upon coordination of a nitrogencontaining ligand to the $\mathrm{P} 450$ heme iron. Titration of recombinant bacterially expressed CYP21A2 with increasing concentrations of abiraterone shows a typical type II shift with an absorption decrease at $410 \mathrm{~nm}$ and an increase at $424 \mathrm{~nm}$ (Figure 4 inset), confirming the computational docking experiments which showed nitrogen-iron co-ordination for binding of abiraterone to CYP21A2 active site. Plotting of the absorbance differences produced a hyperbolic curve which gave a $K_{\mathrm{d}}$ of $6.3 \pm 0.2 \mu \mathrm{M}$ (Figure 4). The micro molar range of the dissociation constant indicates a strong binding of abiraterone to human CYP21A2, which is, however, weaker than that for $17 \mathrm{OH}-\mathrm{PROG}$, which has a $K_{\mathrm{d}}$ value of $0.03 \mu \mathrm{M}$ as reported by Pallan et al. [54].

\subsection{Estimation of the $K_{\mathrm{i}}$ value for abiraterone with purified CYP21A2}

For the determination of a $K_{\mathrm{i}}$ value for abiraterone by the Dixon plot [44], reconstituted in vitro assays using recombinant CYP21A2 were performed with three different $17 \mathrm{OH}-$ progesterone concentrations $(1,2.5$ and $5 \mu \mathrm{M})$ and the addition of increasing amounts of abiraterone $(0.25,0.5,1,2.5$ and $5 \mu \mathrm{M})$. For each $17 \mathrm{OH}-\mathrm{PROG}$ concentration, the reciprocal reaction velocity $(\mathrm{v}=\mathrm{nmol}$ product $/ \mathrm{nmol} \mathrm{CYP} / \mathrm{min})$ was plotted against the respective concentration of abiraterone, resulting in three linear fits, whose interface showed a $K_{\mathrm{i}}$ value of $2.26 \mu \mathrm{M}$. The estimated $K_{\mathrm{i}}$ value agrees with the determined dissociation constant of 6.3 $\mu \mathrm{M}$ which was also measured with the recombinant CYP21A2. The $\mathrm{K}_{\mathrm{i}}$ value obtained using 331 recombinant enzyme was higher when compared to results from cell culture experiments. This 332 could be due to the differences in the two systems and methods used, e.g. purification and 333 reconstitution steps involved in use of bacterially expressed CYP21A2. 


\section{Discussion}

Abiraterone acetate was developed as an inhibitor of CYP17A1 to block androgen production.

The effect of abiraterone has been demonstrated successfully in the treatment of metastatic castrate resistant prostate cancers (mCRPC) [29]. Abiraterone was approved as a treatment of mCRPC with co-administration of prednisolone or prednisone by U.S. Food and Drug Administration (FDA) and also by European Medicines Agency's (EMA) Committee for Medicinal Products for Human Use. The small doses of prednisone or prednisolone positively reduced side effects of abiraterone acetate administration which was associated with increased levels of adrenocorticotropic hormone and steroids upstream of CYP17A1 along with suppression of serum testosterone, downstream androgenic steroids, and estradiol in all patients [55]. Abiraterone is known to have strong (CYP1A2, CYP2D6 and CYP2C8) to moderate (CYP2C9, CYP2C19, CYP3A4, CYP3A5) inhibitory effect on several hepatic drug metabolizing cytochrome $\mathrm{P} 450$ enzymes and is a substrate of CYP3A4 in vitro (https://www.accessdata.fda.gov/drugsatfda_docs/label/2012/202379s004lbl.pdf). Some 349 studies have indicated reduced activity of HSD3B1 and HSD3B2 [56]. Abiraterone is also 350 known to bind to the androgen receptor and produces a dose-dependent decrease in AR levels 351 [57, 58]. However, surprisingly, information about effects of abiraterone on steroid 352 metabolizing enzymes is lacking. Considering the inhibitory effect of abiraterone on multiple 353 hepatic cytochrome P450 enzymes, in addition to its inhibitory effect on CYP17A1, effects of 354 abiraterone on other similar steroid metabolizing cytochrome P450 enzymes should have been 355 investigated. However, information regarding such studies is not available at either 356 manufacturer's web site (www.zytiga.com) or from the FDA drug safety documents 357 (https://www.accessdata.fda.gov/drugsatfda_docs/label/2012/202379s004lbl.pdf) . 
We have previously performed a preliminary analysis of the steroid hydroxylation reactions

of the adrenal carcinoma cell line treated by CYP17A1 inhibitors [26]. The analysis indicated low androgen (DHEAS and testosterone) as well as cortisol production under the abiraterone treatment. Moreover, the steroid profiling, which provided the CYP21A2 activity as a ratio of 17OHP and 11 DOC conversion, showed complete inhibition of CYP21A2 in case of $1 \mu \mathrm{M}$ concentration of abiraterone [26]. In our current study, different concentrations of abiraterone were used to treat the NCI-H295R adrenal carcinoma cell line. Abiraterone caused a dose dependent reduction of CYP21A2 activity. A significantly lower CYP21A2 activity was observed at $0.03 \mu \mathrm{M}$ and higher concentrations of abiraterone with an $\mathrm{IC}_{50}$ value of $25 \mathrm{nM}$. A whole cell steroid analysis performed to observe the global changes in steroid patterns upon abiraterone treatment showed a wide range of altered steroid metabolites (Table 1). In addition to testosterone and dehydroepiandrosterone reduction as expected, we saw changes in corticosterone and cortisol metabolites by abiraterone treatment (Figure 6). Based on these results, we can conclude that abiraterone causes a complex pattern of changes in steroid metabolites due to its inhibition of CYP21A2 activities in addition to inhibition of $17 \alpha-$ hydroxylase and 17,20 lyase activities of CYP17A1.

Further studies were performed to elucidate the binding of abiraterone to CYP21A2. The computational docking of abiraterone into the CYP21A2 crystal structure showed that abiraterone binds closer to the central heme of CYP21A2, which was similar to the binding of abiraterone to the CYP17A1, as observed in crystal structures and spectral binding studies [54, 59]. The predicted model of CYP21A2 and abiraterone binding was confirmed by spectral binding analysis. A complex formation between abiraterone and CYP21A2 was observed as a type II spectral shift upon displacement of a water molecule by the coordination 383 of a nitrogen-containing ligand to the P450 heme iron. Binding of steroid substrates to 
CYP21A2 results in a type I P450 spectra, indicating the effects of substrate binding on the

heme iron spin state equilibrium [54]. In our study, the $\mathrm{K}_{\mathrm{d}}$ Value of the complex of bacterially produced recombinant CYP21A2 with abiraterone was $6.3 \pm 0.2 \mu \mathrm{M}$ indicating a strong affinity. Further experiments were then performed to detect the pattern of enzymatic inhibition of CYP21A2 by abiraterone. A Dixon plot of enzymatic analysis using variable concentrations of substrate as well as inhibitor revealed a competitive / simple mixed inhibition pattern for inhibition of CYP21A2 by abiraterone.

Our studies provide the detailed analysis of the inhibitory effects of abiraterone on CYP21A2 activity. These results indicate that the cortisol production in patients with CRPC who are treated with abiraterone may be affected not only by the inhibition of CYP17A1 but also by the CYP21A2 inhibition. In addition, use of abiraterone in non-cancerous hyperandrogenic disorders like polycystic ovary syndrome requires further caution as inhibition of both the CYP17A1 as well as the CYP21A2, may potentially result in complications associated with lower cortisol levels.

\section{Conflict of Interest}

The authors declare that the research was conducted in the absence of any commercial or financial relationships that could be construed as a potential conflict of interest.

\section{Author Contributions}

Participated in research design: Malikova, Brixius-Anderko, Udhane, Parween, Dick, Bernhardt, Pandey

Conducted experiments: Malikova, Brixius-Anderko, Udhane, Dick, Pandey

Contributed new reagents or analytical tools: Bernhardt

Performed data analysis: Malikova, Brixius-Anderko, Udhane, Parween, Dick, Bernhardt, Pandey

Overall supervision of the project: Pandey

Wrote or contributed the writing of the manuscript: Malikova, Brixius-Anderko, Udhane, Parween, Dick, Bernhardt, Pandey 


\section{Funding}

This work was supported by grants from the Swiss National Science Foundation (31003A134926) to AVP.

\section{Acknowledgments}

We thank Dr. Nasser Dhayat from the Department of Nephrology, Hypertension and Clinical

Pharmacology, University Hospital of Bern, Bern, Switzerland, for providing the steroid

pathway shown in figure 6. We thank Dr. Lina Schiffer for the purification of human POR.

\section{References}

[1] C.E. Flück, A.V. Pandey, Testicular Steroidogenesis, in: M. Simoni, I. Huhtaniemi (Eds.), Endocrinology of the Testis and Male Reproduction, Springer International Publishing, Cham, 2017. pp. 1-29.

[2] C.E. Flück, A.V. Pandey, Steroidogenesis of the testis -- new genes and pathways, Ann Endocrinol (Paris) 75(2) (2014) 40-47.

[3] B.C. Chung, K.J. Matteson, R. Voutilainen, T.K. Mohandas, W.L. Miller, Human cholesterol side-chain cleavage enzyme, P450scc: cDNA cloning, assignment of the gene to chromosome 15, and expression in the placenta, Proc Natl Acad Sci U S A 83(23) (1986) 8962-8966.

[4] S. Nakajin, J.E. Shively, P.M. Yuan, P.F. Hall, Microsomal cytochrome P-450 from neonatal pig testis: two enzymatic activities (17 alpha-hydroxylase and c17,20-lyase) associated with one protein, Biochemistry 20(14) (1981) 4037-4042.

[5] B.C. Chung, J. Picado-Leonard, M. Haniu, M. Bienkowski, P.F. Hall, J.E. Shively, W.L. Miller, Cytochrome P450c17 (steroid 17 alpha-hydroxylase/17,20 lyase): cloning of human adrenal and testis cDNAs indicates the same gene is expressed in both tissues, Proc Natl Acad Sci U S A 84(2) (1987) 407-411.

[6] T. Sakaki, M. Akiyoshi-Shibata, Y. Yabusaki, K. Manabe, H. Murakami, H. Ohkawa, Progesterone metabolism in recombinant yeast simultaneously expressing bovine cytochromes P450c17 (CYP17A1) and P450c21 (CYP21B1) and yeast NADPH-P450 oxidoreductase, Pharmacogenetics 1(2) (1991) 86-93.

[7] T. Yamazaki, K. Nawa, S. Kominami, S. Takemori, Cytochrome P-450(17 alpha,lyase)-mediating pathway of androgen synthesis in bovine adrenocortical cultured cells, Biochim Biophys Acta 1134(2) (1992) 143-148.

[8] W.L. Miller, R.J. Auchus, The molecular biology, biochemistry, and physiology of human steroidogenesis and its disorders, Endocr Rev 32(1) (2011) 81-151.

[9] M.X. Zuber, E.R. Simpson, M.R. Waterman, Expression of bovine 17 alphahydroxylase cytochrome P-450 cDNA in nonsteroidogenic (COS 1) cells, Science 234(4781) (1986) 1258-1261.

[10] S. Nakajin, M. Shinoda, M. Haniu, J.E. Shively, P.F. Hall, C21 steroid side chain cleavage enzyme from porcine adrenal microsomes. Purification and characterization of the 
17 alpha-hydroxylase/C17,20-lyase cytochrome P-450, J Biol Chem 259(6) (1984) 39713976.

[11] J. Lindholm, S. Juul, J.O. Jorgensen, J. Astrup, P. Bjerre, U. Feldt-Rasmussen, C. Hagen, J. Jorgensen, M. Kosteljanetz, L. Kristensen, P. Laurberg, K. Schmidt, J. Weeke, Incidence and late prognosis of cushing's syndrome: a population-based study, J Clin Endocrinol Metab 86(1) (2001) 117-123.

[12] O.M. Dekkers, E. Horváth-Puhó, J.O.L. Jørgensen, S.C. Cannegieter, V. Ehrenstein, J.P. Vandenbroucke, A.M. Pereira, H.T. Sørensen, Multisystem Morbidity and Mortality in Cushing's Syndrome: A Cohort Study, The Journal of Clinical Endocrinology \& Metabolism 98(6) (2013) 2277-2284.

[13] G. Öcal, M. Berberoğlu, Z. Siklar, Z. Aycan, B. Hacıhamdioglu, Ş.S. Erdeve, E. Çamtosun, P. Kocaay, H.I. Ruhi, B.G. Kılıç, A. Tukun, Clinical Review of 95 Patients with 46,XX Disorders of Sex Development Based on the New Chicago Classification, Journal of Pediatric and Adolescent Gynecology 28(1) (2015) 6-11.

[14] C.E. Flück, M. Meyer-Boni, A.V. Pandey, P. Kempna, W.L. Miller, E.J. Schoenle, A. Biason-Lauber, Why boys will be boys: two pathways of fetal testicular androgen biosynthesis are needed for male sexual differentiation, Am J Hum Genet 89(2) (2011) 201218.

[15] E. Carmina, F. Rosato, A. Jannì, M. Rizzo, R.A. Longo, Relative Prevalence of Different Androgen Excess Disorders in 950 Women Referred because of Clinical Hyperandrogenism, The Journal of Clinical Endocrinology \& Metabolism 91(1) (2006) 2-6. [16] A. Kumar, K.S. Woods, A.A. Bartolucci, R. Azziz, Prevalence of adrenal androgen excess in patients with the polycystic ovary syndrome (PCOS), Clinical Endocrinology 62(6) (2005) 644-649.

[17] R. Azziz, L.A. Sanchez, E.S. Knochenhauer, C. Moran, J. Lazenby, K.C. Stephens, K. Taylor, L.R. Boots, Androgen Excess in Women: Experience with Over 1000 Consecutive Patients, The Journal of Clinical Endocrinology \& Metabolism 89(2) (2004) 453-462.

[18] N. Krone, W. Arlt, Genetics of congenital adrenal hyperplasia, Best Practice \& Research Clinical Endocrinology \& Metabolism 23(2) (2009) 181-192.

[19] E.N. Gönç, Z.A. Özön, M.D. Çakır, A. Alikaşifoğlu, N. Kandemir, Need for Comprehensive Hormonal Workup in the Management of Adrenocortical Tumors in Children, Journal of Clinical Research in Pediatric Endocrinology 6(2) (2014) 68-73.

[20] M. Fleseriu, F. Castinetti, Updates on the role of adrenal steroidogenesis inhibitors in Cushing's syndrome: a focus on novel therapies, Pituitary 19(6) (2016) 643-653.

[21] X. Bertagna, R. Pivonello, M. Fleseriu, Y. Zhang, P. Robinson, A. Taylor, C.E.

Watson, M. Maldonado, A.H. Hamrahian, M. Boscaro, B.M.K. Biller, LCI699, a Potent $11 \beta-$ hydroxylase Inhibitor, Normalizes Urinary Cortisol in Patients With Cushing's Disease: Results From a Multicenter, Proof-of-Concept Study, The Journal of Clinical Endocrinology \& Metabolism 99(4) (2014) 1375-1383.

[22] M. Fleseriu, R. Pivonello, J. Young, A.H. Hamrahian, M.E. Molitch, C. Shimizu, T. Tanaka, A. Shimatsu, T. White, A. Hilliard, C. Tian, N. Sauter, B.M.K. Biller, X. Bertagna, Osilodrostat, a potent oral $11 \beta$-hydroxylase inhibitor: 22 -week, prospective, Phase II study in Cushing's disease, Pituitary 19 (2016) 138-148.

[23] B. Montgomery, M.A. Eisenberger, M.B. Rettig, F. Chu, R. Pili, J.J. Stephenson, N.J. Vogelzang, A.J. Koletsky, L.T. Nordquist, W.J. Edenfield, K. Mamlouk, K.J. Ferrante, M.-E. Taplin, Androgen Receptor Modulation Optimized for Response (ARMOR) Phase I and II Studies: Galeterone for the Treatment of Castration-Resistant Prostate Cancer, Clinical Cancer Research 22(6) (2016) 1356-1363.

[24] K. Fizazi, R. Jones, S. Oudard, E. Efstathiou, F. Saad, R.d. Wit, J.D. Bono, F.M. Cruz, G. Fountzilas, A. Ulys, F. Carcano, N. Agarwal, D. Agus, J. Bellmunt, D.P. Petrylak, S.-Y. 
Lee, I.J. Webb, B. Tejura, N. Borgstein, R. Dreicer, Phase III, Randomized, Double-Blind, Multicenter Trial Comparing Orteronel (TAK-700) Plus Prednisone With Placebo Plus Prednisone in Patients With Metastatic Castration-Resistant Prostate Cancer That Has Progressed During or After Docetaxel-Based Therapy: ELM-PC 5, Journal of Clinical Oncology 33(7) (2015) 723-731. [25] T. Kaku, T. Hitaka, A. Ojida, N. Matsunaga, M. Adachi, T. Tanaka, T. Hara, M. Yamaoka, M. Kusaka, T. Okuda, S. Asahi, S. Furuya, A. Tasaka, Discovery of orteronel (TAK-700), a naphthylmethylimidazole derivative, as a highly selective 17,20-lyase inhibitor with potential utility in the treatment of prostate cancer, Bioorganic \& medicinal chemistry 19(21) (2011) 6383-6399.

[26] S.S. Udhane, B. Dick, Q. Hu, R.W. Hartmann, A.V. Pandey, Specificity of antiprostate cancer CYP17A1 inhibitors on androgen biosynthesis, Biochem Biophys Res Commun 477(4) (2016) 1005-1010.

[27] I. Schuster, R. Bernhardt, Inhibition of cytochromes p450: existing and new promising therapeutic targets, Drug Metab Rev 39(2-3) (2007) 481-499.

[28] T. Hakki, R. Bernhardt, CYP17- and CYP11B-dependent steroid hydroxylases as drug development targets, Pharmacol Ther 111(1) (2006) 27-52.

[29] B.A. Gartrell, F. Saad, Abiraterone in the management of castration-resistant prostate cancer prior to chemotherapy, Therapeutic advances in urology 7(4) (2015) 194-202.

[30] L. Ramudo Cela, J. Balea Filgueiras, J.R. Vizoso Hermida, I. Martin Herranz, Study of cases of abiraterone discontinuation due to toxicity in pre-chemotherapy after 1 year's experience, J Oncol Pharm Pract (2016).

[31] Z. Li, M. Alyamani, J. Li, K. Rogacki, M. Abazeed, S.K. Upadhyay, S.P. Balk, M.-E. Taplin, R.J. Auchus, N. Sharifi, Redirecting abiraterone metabolism to fine-tune prostate cancer anti-androgen therapy, Nature 533(7604) (2016) 547-551.

[32] S. Bonomo, C.H. Hansen, E.M. Petrunak, E.E. Scott, B. Styrishave, F.S. Jorgensen, L. Olsen, Promising Tools in Prostate Cancer Research: Selective Non-Steroidal Cytochrome P450 17A1 Inhibitors, Sci Rep 6 (2016) 29468.

[33] N. Sharifi, Prostate cancer: CYP17A1 inhibitor failure-lessons for future drug development, Nature reviews. Urology 12(5) (2015) 245-246.

[34] A.V. Pandey, C.E. Flück, NADPH P450 oxidoreductase: structure, function, and pathology of diseases, Pharmacol Ther 138(2) (2013) 229-254.

[35] P.W. Speiser, R. Azziz, L.S. Baskin, L. Ghizzoni, T.W. Hensle, D.P. Merke, H.F.L. Meyer-Bahlburg, W.L. Miller, V.M. Montori, S.E. Oberfield, M. Ritzen, P.C. White, Congenital Adrenal Hyperplasia Due to Steroid 21-Hydroxylase Deficiency: An Endocrine Society Clinical Practice Guideline, The Journal of Clinical Endocrinology \& Metabolism 95(9) (2010) 4133-4160.

[36] M. Janner, A.V. Pandey, P.E. Mullis, C.E. Flück, Clinical and biochemical description of a novel CYP21A2 gene mutation 962_963insA using a new 3D model for the P450c21 protein, Eur J Endocrinol 155(1) (2006) 143-151.

[37] S. Brixius-Anderko, L. Schiffer, F. Hannemann, B. Janocha, R. Bernhardt, A CYP21A2 based whole-cell system in Escherichia coli for the biotechnological production of premedrol, Microb Cell Fact 14 (2015) 135.

[38] L. Schiffer, S. Brixius-Anderko, F. Hannemann, J. Zapp, J. Neunzig, M. Thevis, R. Bernhardt, Metabolism of Oral Turinabol by Human Steroid Hormone-Synthesizing Cytochrome P450 Enzymes, Drug Metab Dispos 44(2) (2016) 227-237.

[39] L.H. Zhang, H. Rodriguez, S. Ohno, W.L. Miller, Serine phosphorylation of human P450c17 increases 17,20-lyase activity: implications for adrenarche and the polycystic ovary syndrome, Proc Natl Acad Sci U S A 92(23) (1995) 10619-10623. 
[40] A.V. Pandey, S.H. Mellon, W.L. Miller, Protein phosphatase 2A and phosphoprotein SET regulate androgen production by P450c17, J Biol Chem 278(5) (2003) 2837-2844. [41] A.V. Pandey, W.L. Miller, Regulation of 17,20 lyase activity by cytochrome b5 and by serine phosphorylation of P450c17, J Biol Chem 280(14) (2005) 13265-13271.

[42] S. Parween, F. Roucher-Boulez, C.E. Flück, A. Lienhardt-Roussie, D. Mallet, Y. Morel, A.V. Pandey, P450 Oxidoreductase Deficiency: Loss of Activity Caused by Protein Instability From a Novel L374H Mutation, J Clin Endocrinol Metab 101(12) (2016) 47894798.

[43] L. Michaelis, M.L. Menten, Die Kinetik der Invertinwirkung, Biochem Z 49 (1913) 333-369.

[44] M. Dixon, The determination of enzyme inhibitor constants, Biochem J 55(1) (1953) 170-171.

[45] C. Quattropani, B. Vogt, A. Odermatt, B. Dick, B.M. Frey, F.J. Frey, Reduced activity of 11 beta-hydroxysteroid dehydrogenase in patients with cholestasis, J Clin Invest 108(9) (2001) 1299-1305.

[46] C.H. Shackleton, Mass spectrometry in the diagnosis of steroid-related disorders and in hypertension research, J Steroid Biochem Mol Biol 45(1-3) (1993) 127-140.

[47] E. Krieger, T. Darden, S.B. Nabuurs, A. Finkelstein, G. Vriend, Making optimal use of empirical energy functions: force-field parameterization in crystal space, Proteins 57(4) (2004) 678-683.

[48] G. Vriend, WHAT IF: a molecular modeling and drug design program, J Mol Graph 8(1) (1990) 52-56, 29.

[49] Y. Duan, C. Wu, S. Chowdhury, M.C. Lee, G. Xiong, W. Zhang, R. Yang, P. Cieplak, R. Luo, T. Lee, J. Caldwell, J. Wang, P. Kollman, A point-charge force field for molecular mechanics simulations of proteins based on condensed-phase quantum mechanical calculations, Journal of Computational Chemistry 24(16) (2003) 1999-2012.

[50] W.L. Jorgensen, J. Tirado-Rives, Potential energy functions for atomic-level simulations of water and organic and biomolecular systems, Proc Natl Acad Sci U S A 102(19) (2005) 6665-6670.

[51] O. Trott, A.J. Olson, AutoDock Vina: Improving the speed and accuracy of docking with a new scoring function, efficient optimization, and multithreading, Journal of Computational Chemistry 31(2) (2010) 455-461.

[52] Y. Cheng, W.H. Prusoff, Relationship between the inhibition constant (K1) and the concentration of inhibitor which causes 50 per cent inhibition (I50) of an enzymatic reaction, Biochem Pharmacol 22(23) (1973) 3099-3108.

[53] B.T. Burlingham, T.S. Widlanski, An intuitive look at the relationship of K-i and IC50: A more general use for the Dixon plot, J Chem Educ 80(2) (2003) 214-218.

[54] P.S. Pallan, L.D. Nagy, L. Lei, E. Gonzalez, V.M. Kramlinger, C.M. Azumaya, Z. Wawrzak, M.R. Waterman, F.P. Guengerich, M. Egli, Structural and kinetic basis of steroid 17alpha,20-lyase activity in teleost fish cytochrome P450 17A1 and its absence in cytochrome P450 17A2, J Biol Chem 290(6) (2015) 3248-3268.

[55] G. Attard, A.H. Reid, T.A. Yap, F. Raynaud, M. Dowsett, S. Settatree, M. Barrett, C. Parker, V. Martins, E. Folkerd, J. Clark, C.S. Cooper, S.B. Kaye, D. Dearnaley, G. Lee, J.S. de Bono, Phase I clinical trial of a selective inhibitor of CYP17, abiraterone acetate, confirms that castration-resistant prostate cancer commonly remains hormone driven, Journal of clinical oncology : official journal of the American Society of Clinical Oncology 26(28) (2008) 4563-4571.

[56] R. Li, K. Evaul, K.K. Sharma, K.H. Chang, J. Yoshimoto, J. Liu, R.J. Auchus, N. Sharifi, Abiraterone inhibits 3beta-hydroxysteroid dehydrogenase: a rationale for increasing 
603 drug exposure in castration-resistant prostate cancer, Clinical cancer research : an official journal of the American Association for Cancer Research 18(13) (2012) 3571-3579. [57] H.S. Soifer, N. Souleimanian, S. Wu, A.M. Voskresenskiy, F.K. Collak, B. Cinar, C.A. Stein, Direct regulation of androgen receptor activity by potent CYP17 inhibitors in prostate cancer cells, J Biol Chem 287(6) (2012) 3777-3787.

[58] J. Richards, A.C. Lim, C.W. Hay, A.E. Taylor, A. Wingate, K. Nowakowska, C. Pezaro, S. Carreira, J. Goodall, W. Arlt, I.J. McEwan, J.S. de Bono, G. Attard, Interactions of abiraterone, eplerenone, and prednisolone with wild-type and mutant androgen receptor: a

rationale for increasing abiraterone exposure or combining with MDV3100, Cancer Res 72(9) (2012) 2176-2182.

[59] R. Yadav, E.M. Petrunak, D.F. Estrada, E.E. Scott, Structural insights into the function of steroidogenic cytochrome P450 17A1, Mol Cell Endocrinol 441 (2017) 68-75. 
Tables

Table 1: Effect of abiraterone on steroid production by human adrenal cells.

\begin{tabular}{|c|c|c|c|}
\hline Steroid Metabolite & Abbreviation & DMSO & Abiraterone \\
\hline Androsterone & ANDRO & 0.390881 & 6.226052 \\
\hline Etiocholanolone & ETIO & 0.109623 & 3.321062 \\
\hline Androstenediol & $5 \alpha \mathrm{AD} 3 \alpha 17 \beta$ & 0.30697 & 0.465213 \\
\hline 11-Oxo-Etiocholanolon & 11-OXO-ETIO & N.A. & 0.187621 \\
\hline 11ß-Hydroxy-Androsterone & 11-OH-ANDRO & 0.188208 & 3.451147 \\
\hline $11 \beta$-Hydroxy-Etiocholanolone & 11-OH-ETIO & N.A. & 2.134756 \\
\hline Dehydroepiandrosterone & DHEA & 1.436706 & 0.144953 \\
\hline 5-Androstene- $3 \beta, 17 \beta$-diol & $5-\mathrm{AD}-17 \beta$ & 0.340096 & 0.215782 \\
\hline 16 $\alpha$-Hydroxy-DHEA & $16 \alpha-\mathrm{OH}-\mathrm{DHEA}$ & 2.154509 & 1.740921 \\
\hline 5-Androstene-3 $3,16 \alpha, 17 \beta$-triol & 5-AT & 0.234827 & 0.311715 \\
\hline 5-Pregnene-3 $\beta, 16 \alpha, 17 \beta$-triol & 5-PT & 1.371897 & 0.124343 \\
\hline Testosterone & TESTOSTERONE & 1.613952 & 0.413544 \\
\hline $5 \alpha$-Dihydrotestosterone & $5 \alpha$-DIHYDROTEST & 0.182893 & N.A. \\
\hline Estriol & ESTRIOL & 0.07959 & 0.044161 \\
\hline $17 \beta$-Estradiol & 17 $\beta$-ESTRADIOL & N.A. & 0.027509 \\
\hline 17-Hydroxypregnanolone & 17-HP & 0.023376 & $\mathbf{1 . 0 3 0 3 8 9}$ \\
\hline Pregnanediol & PD & 1.670818 & 0.715222 \\
\hline Pregnanetriol & $\mathrm{PT}$ & 0.168326 & 3.385257 \\
\hline \multicolumn{4}{|l|}{ 11-Deoxycortisol-Metabolite } \\
\hline Tetrahydrosubstance S & THS & N.A. & 0.263843 \\
\hline \multicolumn{4}{|l|}{ Corticosterone-Metabolite } \\
\hline Tetrahydro DOC & THDOC & 2.087659 & 0.067438 \\
\hline Tetrahydro dehydrocorticosterone & THA & N.A. & 0.371549 \\
\hline Tetrahydrocorticosterone & THB & N.A. & 0.780605 \\
\hline $5 \alpha$-Tetrahydrocorticosterone & $5 \alpha-\mathrm{THB}$ & N.A. & $\mathbf{1 . 1 3 2 7 2 5}$ \\
\hline 18-Hydroxy-tetrahydrocompound A & 18-OH-THA & N.A. & N.A. \\
\hline \multicolumn{4}{|l|}{ Cortisol-Metabolite } \\
\hline Cortison & CORTISONE & N.A. & 0.5454 \\
\hline Tetrahydrocortison & THE & 0.192633 & 12.27504 \\
\hline$\alpha$-Cortolon & $\alpha$-CORTOLONE & 0.006468 & 2.949182 \\
\hline$\beta$-Cortolon & $\beta$-CORTOLONE & N.A. & 1.38639 \\
\hline $20 \alpha$-Dihydrocortison & $20 \alpha-\mathrm{DHE}$ & N.A. & 0.084738 \\
\hline 20 $\beta$-Dihydrocortison & $20 \beta-\mathrm{DHE}$ & N.A. & 0.195689 \\
\hline Cortisol & CORTISOL & 1.86521 & 0.747982 \\
\hline Tetrahydrocortisol & THF & 0.095437 & 8.012946 \\
\hline $5 \alpha$-Tetrahydrocortisol & $5 \alpha-\mathrm{THF}$ & 0.274516 & 7.184058 \\
\hline$\alpha$-Cortol & $\alpha$-CORTOL & N.A. & 1.813959 \\
\hline$\beta$-Cortol & $\beta$-CORTOL & N.A. & 1.653822 \\
\hline 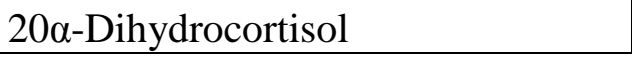 & $20 \alpha-\mathrm{DHF}$ & 0.315156 & 0.507297 \\
\hline
\end{tabular}


Table 2: Computational binding energy, dissociation contacts and interacting residues for 3626 abiraterone binding with CYP21A2 compared to CYP17A1.

\begin{tabular}{|c|c|c|c|}
\hline & $\begin{array}{l}\text { Binding Energy } \\
\text { (kcal/mol) }\end{array}$ & $\begin{array}{l}\text { Dissociation } \\
\text { constant (nM) }\end{array}$ & Contacting residues \\
\hline $\begin{array}{l}\text { CYP17A1 with } \\
\text { PROG }\end{array}$ & 10.6 & 14.66 & $\begin{array}{lll}\text { ALA113 } & \text { PHE114 } & \text { ASN202 } \\
\text { ILE205 } & \text { ILE206 } & \text { LEU209 } \\
\text { ARG239 } & \text { GLY297 } & \text { ASP298 } \\
\text { GLY301 } & \text { ALA302 } & \text { THR306 } \\
\text { ALA367 } & \text { ILE371 } & \text { VAL482 } \\
\text { VAL483 } & \text { HEME } & \end{array}$ \\
\hline $\begin{array}{l}\text { CYP21A2 with } \\
\text { PROG }\end{array}$ & 12.7 & 0.49 & $\begin{array}{lll}\text { VAL101 } & \text { ASP107 } & \text { SER109 } \\
\text { LEU110 } & \text { VAL198 } & \text { LEU199 } \\
\text { TRP202 } & \text { LEU227 } & \text { ILE231 } \\
\text { ARG234 } & \text { MET284 } & \text { VAL287 } \\
\text { ASP288 } & \text { ILE291 } & \text { GLY292 } \\
\text { THR296 } & \text { VAL360 } & \text { LEU364 } \\
\text { VAL470 } & \text { ILE471 } & \text { HEME }\end{array}$ \\
\hline $\begin{array}{l}\text { CYP17A1 with } \\
\text { Abiraterone }\end{array}$ & 12.5 & 0.69 & $\begin{array}{lll}\text { ALA113 } & \text { PHE114 } & \text { TYR201 } \\
\text { ASN202 } & \text { ILE205 } & \text { ILE206 } \\
\text { LEU209 } & \text { ARG239 } & \text { GLY297 } \\
\text { ASP298 } & \text { GLY301 } & \text { ALA302 } \\
\text { GLU305 } & \text { THR306 } & \text { VAL366 } \\
\text { ALA367 } & \text { LEU370 } & \text { ILE371 } \\
\text { VAL482 } & \text { VAL483 } & \text { HEME } \\
\end{array}$ \\
\hline $\begin{array}{l}\text { CYP21A2 with } \\
\text { Abiraterone }\end{array}$ & 13.2 & 0.20 & $\begin{array}{lll}\text { VAL101 } & \text { ASP107 } & \text { SER109 } \\
\text { LEU110 } & \text { VAL198 } & \text { LEU199 } \\
\text { TRP202 } & \text { LEU227 } & \text { ILE231 } \\
\text { ARG234 } & \text { MET284 } & \text { VAL287 } \\
\text { ASP288 } & \text { ILE291 } & \text { GLY292 } \\
\text { THR296 } & \text { VAL359 } & \text { VAL360 } \\
\text { LEU364 } & \text { VAL470 } & \text { ILE471 } \\
\text { HEME } & & \\
\end{array}$ \\
\hline
\end{tabular}




\title{
Figure legends
}

Figure 1. Pathway of steroid hormone production in humans with of roles of CYP21A2 and

CYP17A1 in humans. Cholesterol is transported to mitochondrion by steroidogenic acute regulatory protein (StAR), where CYP11A1 converts it to pregnenolone. The pregnenolone metabolized in the endoplasmic reticulum to 17OHPreg, DHEA by CYP17A1 and androstenedione or androstenediol and this process continues to production of testosterone. The alternate pathway of steroid metabolism proceeds from $17 \mathrm{OHPreg}$ to $17 \mathrm{OHProg}, 17 \mathrm{OH}-$ DHP, 17OH-Allo, androsterone, androstanediol (A'diol) and then to DHT in the testis. DHEA is converted to androstenedione and then to testosterone, which is further metabolized to estrogens.

\begin{abstract}
Abbreviations: CYP11A1 (P450scc, cholesterol side-chain cleavage enzyme), StAR
(steroidogenic acute regulatory protein), FDX1, Adrenodoxin; FDXR, NADPH adrenodoxin

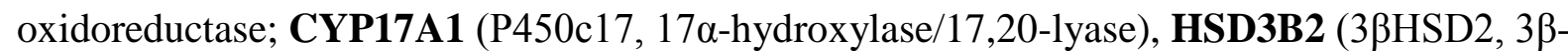
hydroxysteroid dehydrogenase, type 2), CYB5, cytochrome $b_{5}$; POR, P450 oxidoreductase;
\end{abstract} HSD17B3 (17ßHSD3, 17ß-hydroxysteroid dehydrogenase, type 3), and SRD5A2 (5 $\alpha$ reductase, type 2). The alternative pathway has four additional enzymes: SRD5A1 (5 $\alpha-$ reductase, type 1); AKR1C2 (Aldo-keto reductase 1C2, 3aHSD3) and AKR1C4 Aldo-keto

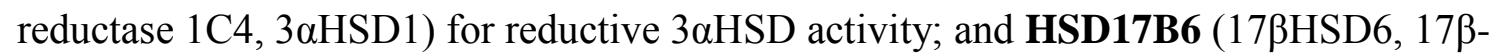
hydroxysteroid dehydrogenase, type 6) and/or AKR1C2/4 for oxidative 3 $\alpha$ HSD activity. Full steroid names: 17OHPreg, 17-hydroxypregnenolone; 17OHProg, 17-hydroxyprogesterone;

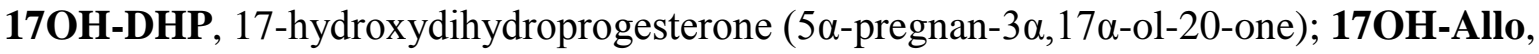
17-hydroxyallopregnanolone (5 $\alpha$-pregnan-3 $\alpha, 17 \alpha$-diol-20-one; P'diol); DHEA, dehydroepiandrosterone. 
Figure 2. Inhibition of CYP21A2 activity by abiraterone in human adrenal cells. The 21-

hydroxylase activity was monitored in H295R cells treated with control (DMSO) and 0.001 to $1 \mu \mathrm{M}$ abiraterone with two different concentrations of the substrate for $24 \mathrm{~h}$. CYP21A2 activities were measured by monitoring the conversion of $\left[{ }^{3} \mathrm{H}\right] 17 \mathrm{OH}-\mathrm{PROG}(17 \alpha-$ hydroxyprogesterone) to 11-deoxycortisol. Data are presented as mean \pm SD of three independent experiments. A. A dose response curve showing the effect of increasing concentrations of abiraterone on CYP21A2 activity. B. A Dixon plot for calculating the Ki values of abiraterone for inhibition of CYP21A2 activity. A $K_{i}$ value of $23 \mathrm{nM}$ was obtained for inhibition of CYP21A2 activity by abiraterone. 17OH-PROG, 17 $\alpha$-hydroxyprogesterone; 11-DOC, 11-deoxycortisol.

Figure 4. Binding spectra of abiraterone with CYP21A2. To confirm the inhibition in cell A. Abiraterone docking into CYP21A2 structure. Abiraterone was docked into the structure of CYP21A2 and found to bind like its native substrate, progesterone. B. A close up of abiraterone docked into CYP21A2 compared to its substrate. C. Abiraterone binds to heme through nitrogen-iron co-ordination. D. A close up of abiraterone bound to CYP17A1. Binding of abiraterone to CYP21A2 is similar to CYP17A1. These data are in line with our findings of the inhibitory effects of abiraterone on CYP21A2 in addition to inhibition of CYP17A1 activities. experiments and computational binding, we carried out spectral binding analysis for the interaction of abiraterone with CYP21A2. Titration of CYP21A2 with increasing concentrations of abiraterone showed a type II shift indicating nitrogen-iron complex as indicated by an absorption decrease at $410 \mathrm{~nm}$ and an increase at $424 \mathrm{~nm}$ (inset). The 
682 difference of the absorbance maximum and minimum plotted against the respective ligand

1 3 4 (1) concentration of each titrating step results in a hyperbolic regression curve revealing a $K_{\mathrm{d}}$ value of $6.3 \pm 0.2 \mu \mathrm{M}$.

Figure 5. Inhibition of recombinant human CYP21A2 activity by abiraterone. To further verify the results obtained from cell experiments, we used recombinant bacterially expressed CYP21A2 for determining the inhibition parameters of abiraterone on CYP21A2. A Dixon Plot (1/v vs inhibitor concentration) at three different concentrations of substrate is shown. Abiraterone inhibited the recombinant CYP21A2 activity with an estimated Ki value of 2.26 $\mu \mathrm{M}$.

693 Figure 6. A schematic representation of the effect of abiraterone on steroidogenesis. Steroid 694 metabolites changes are based on data in Table 1. 
Cholesterol

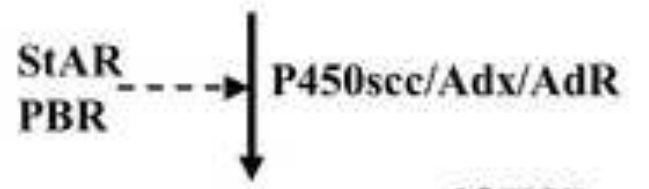

Pregnenolone $\stackrel{\text { 3ßHSD }}{\longrightarrow}$ Progesterone

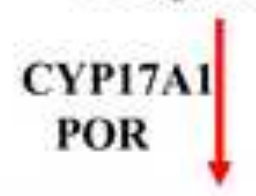

17OH-Pregnenolone $3 \beta \mathrm{HSD}$

CYP17A1
$\mathrm{POR} /\left(\mathrm{b}_{5}\right)$

17ßHSD1 $1 \uparrow 17 \beta$ DHSD2

Androstenediol

$5 \alpha$-Reductase1 \& 2

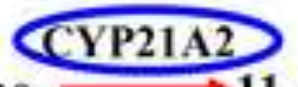
POR

CYP21A2 11-Deoxycortisol CYP11B1

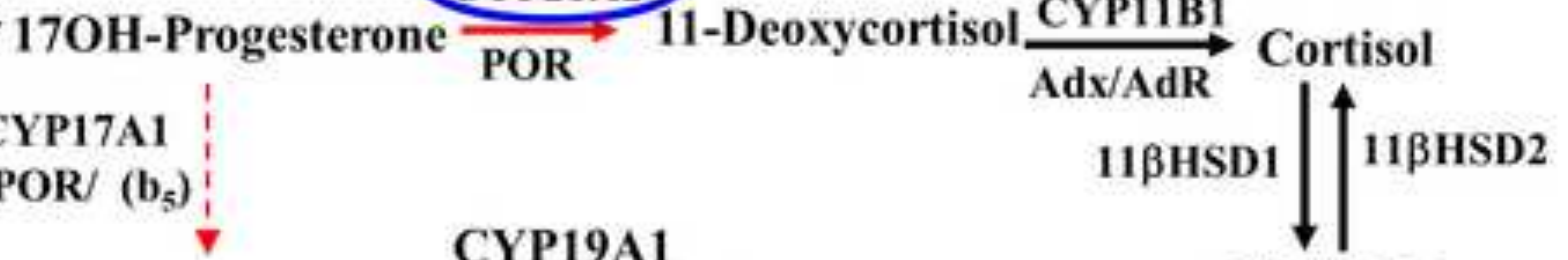

Cortisone

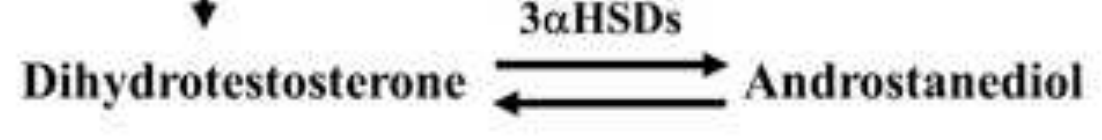

$\underset{\mathrm{Adx} / \mathrm{AdR}}{\stackrel{\mathrm{d}}{\mathrm{d}} \text { Cortisol }}$

Aldosterone

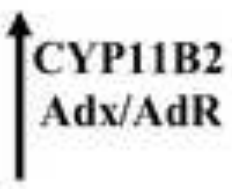

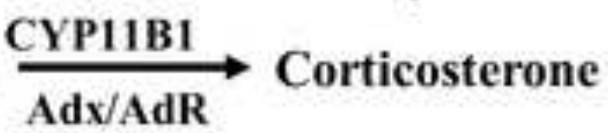

$\longrightarrow$ EOR $\longrightarrow$ Estrone 17ßHSD2

.

$\underset{\text { POR }}{\longrightarrow}$ Estradiol

$3 \alpha$ HSDs

drostanediol 
Figure 2

Click here to download high resolution image

A

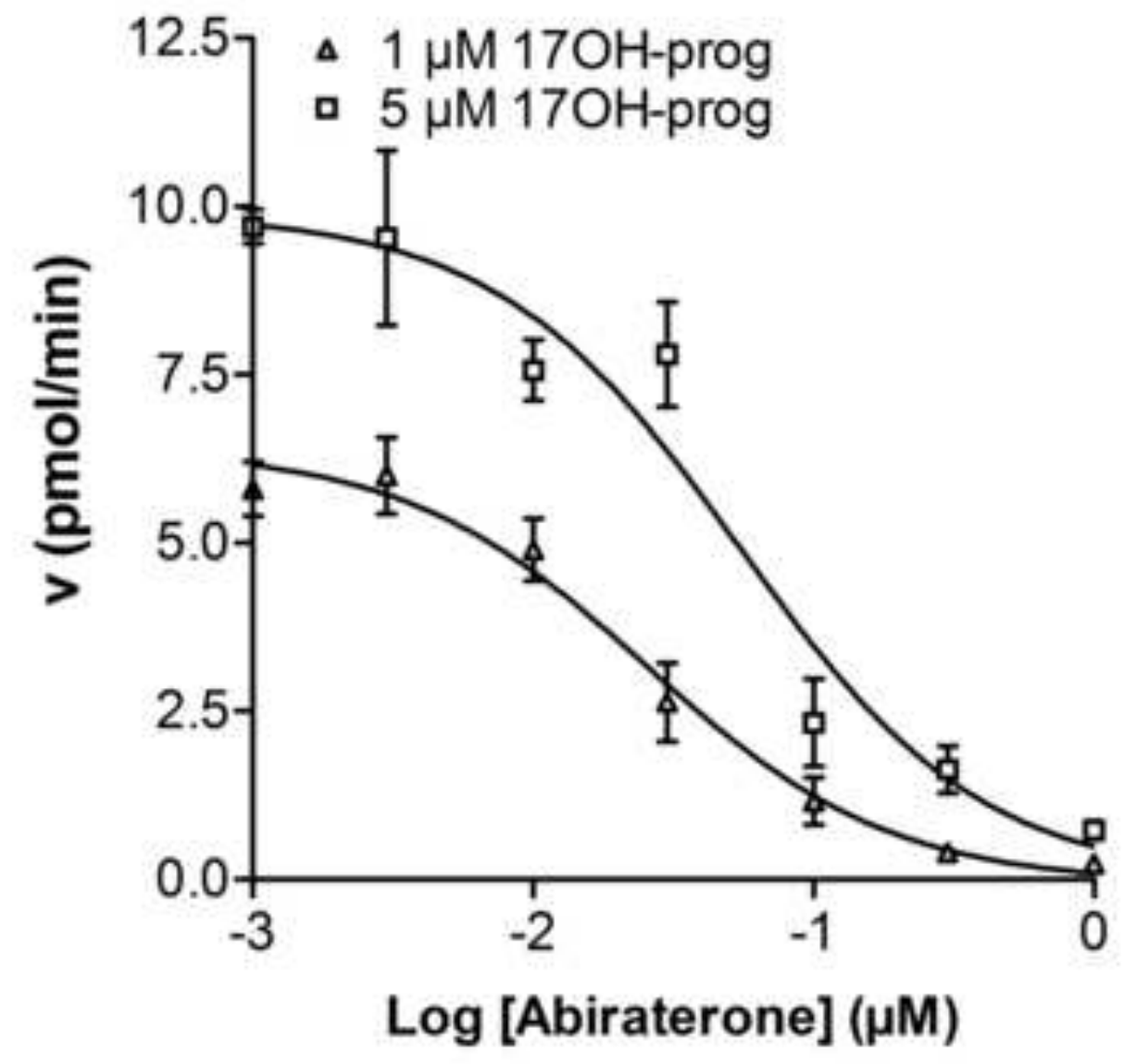

B

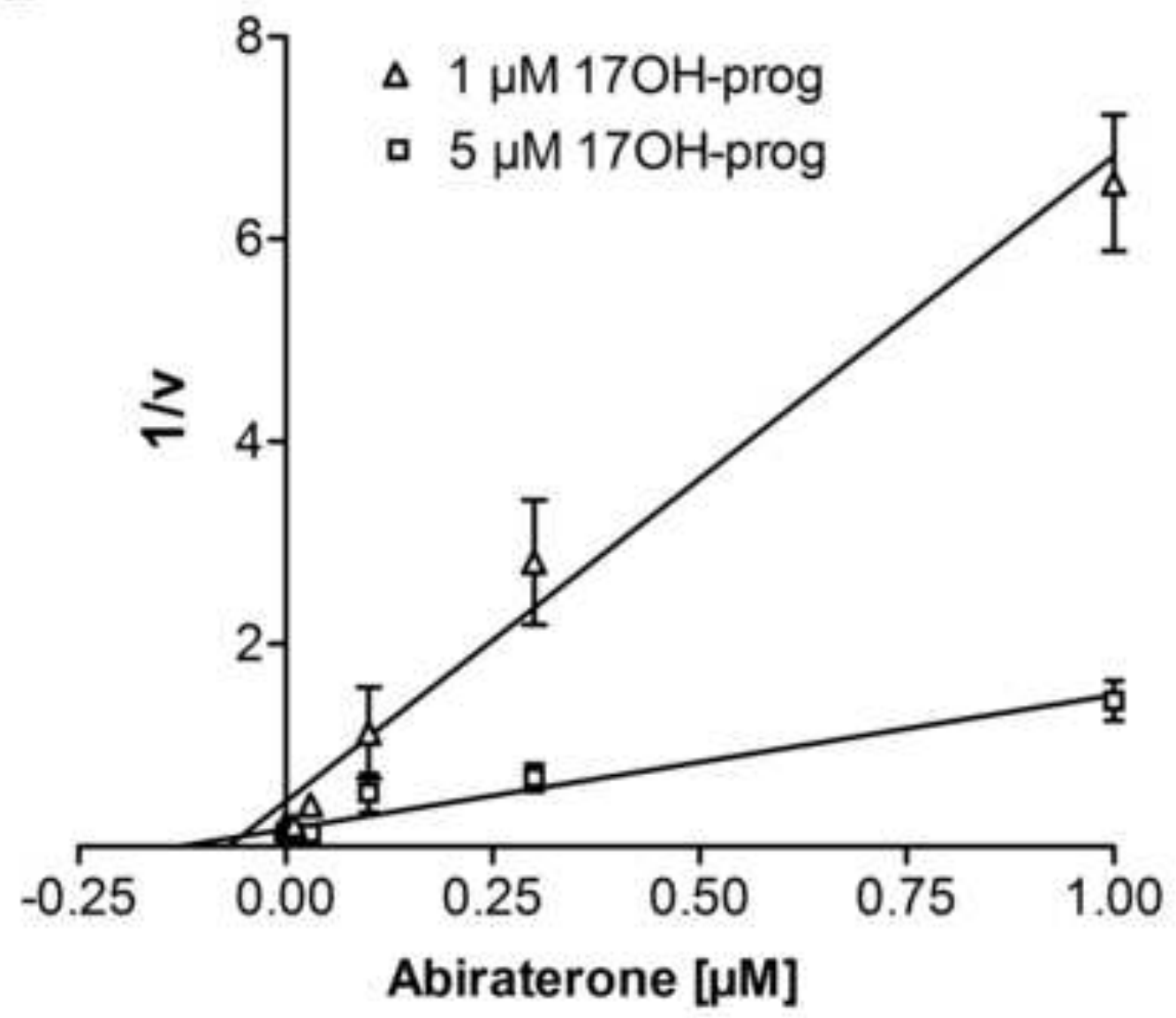


Click here to download high resolution image

A

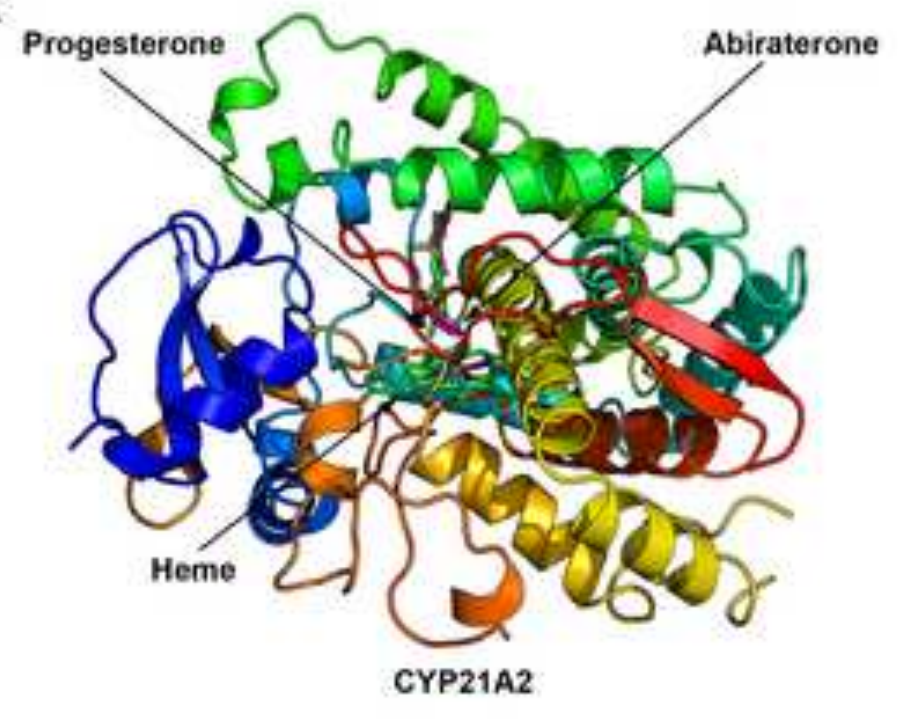

B

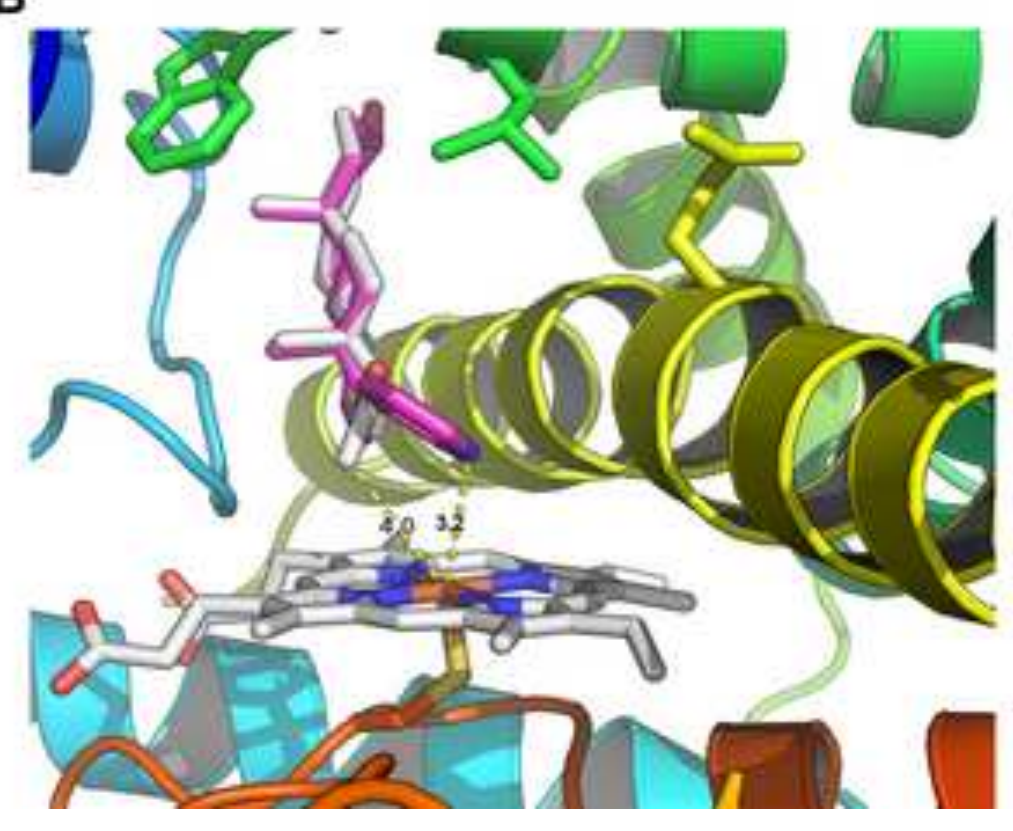

C

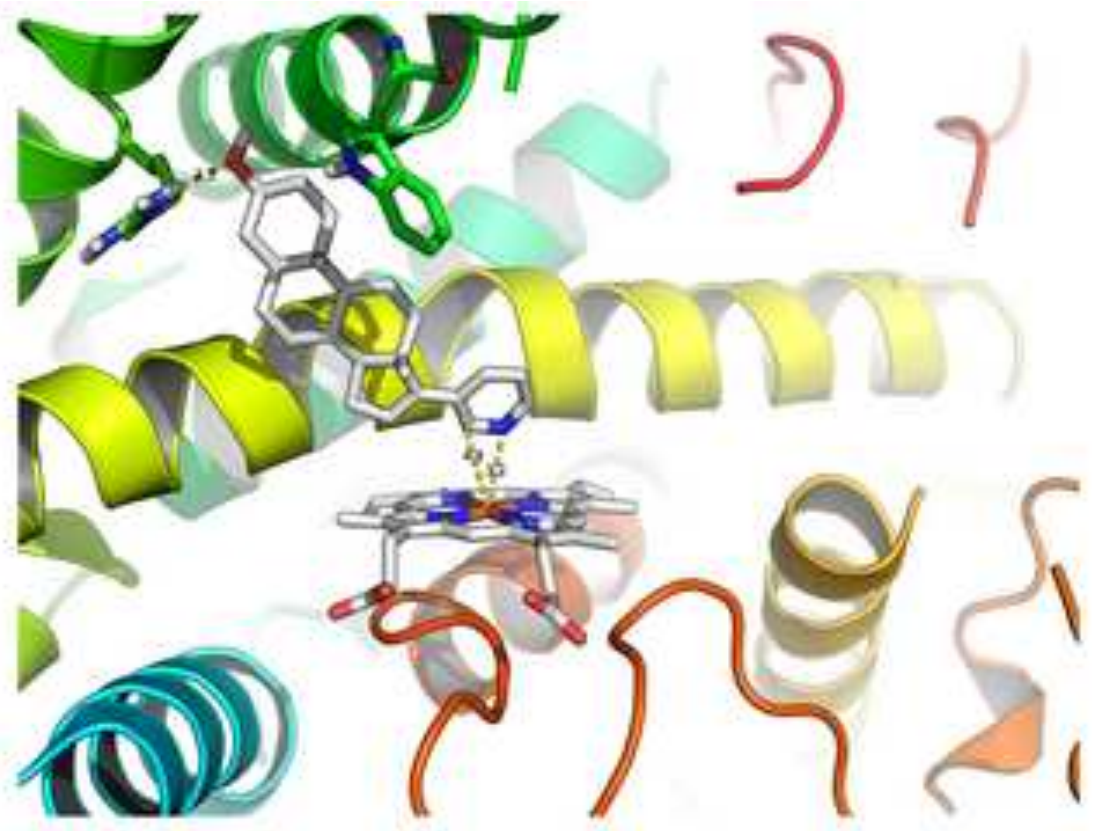

D

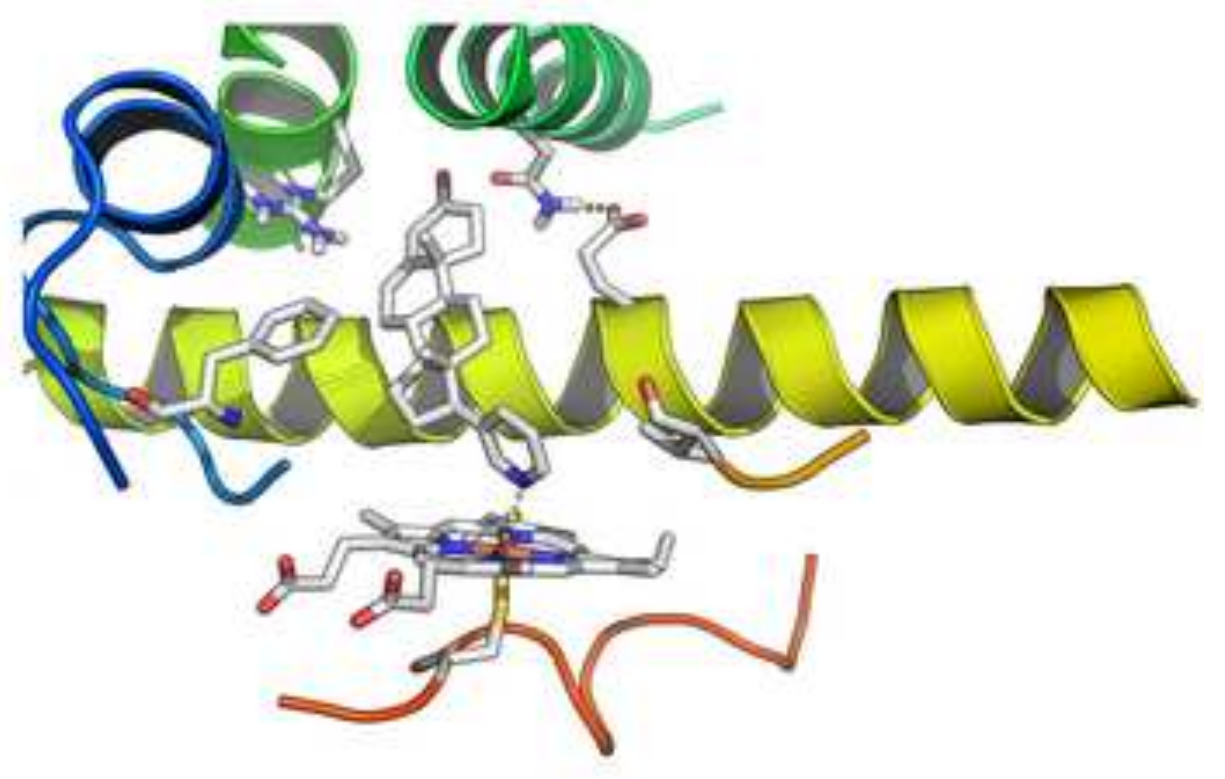




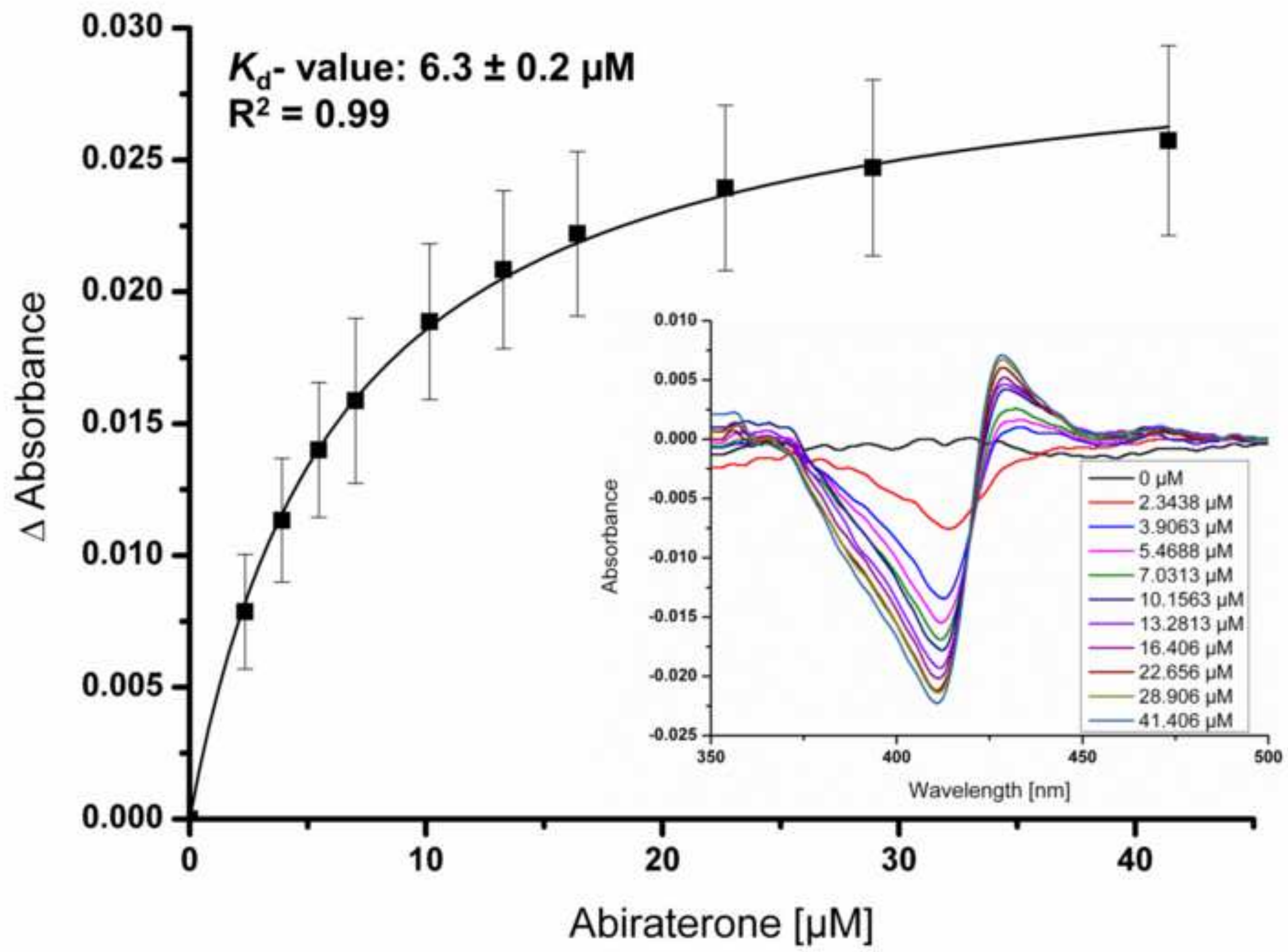




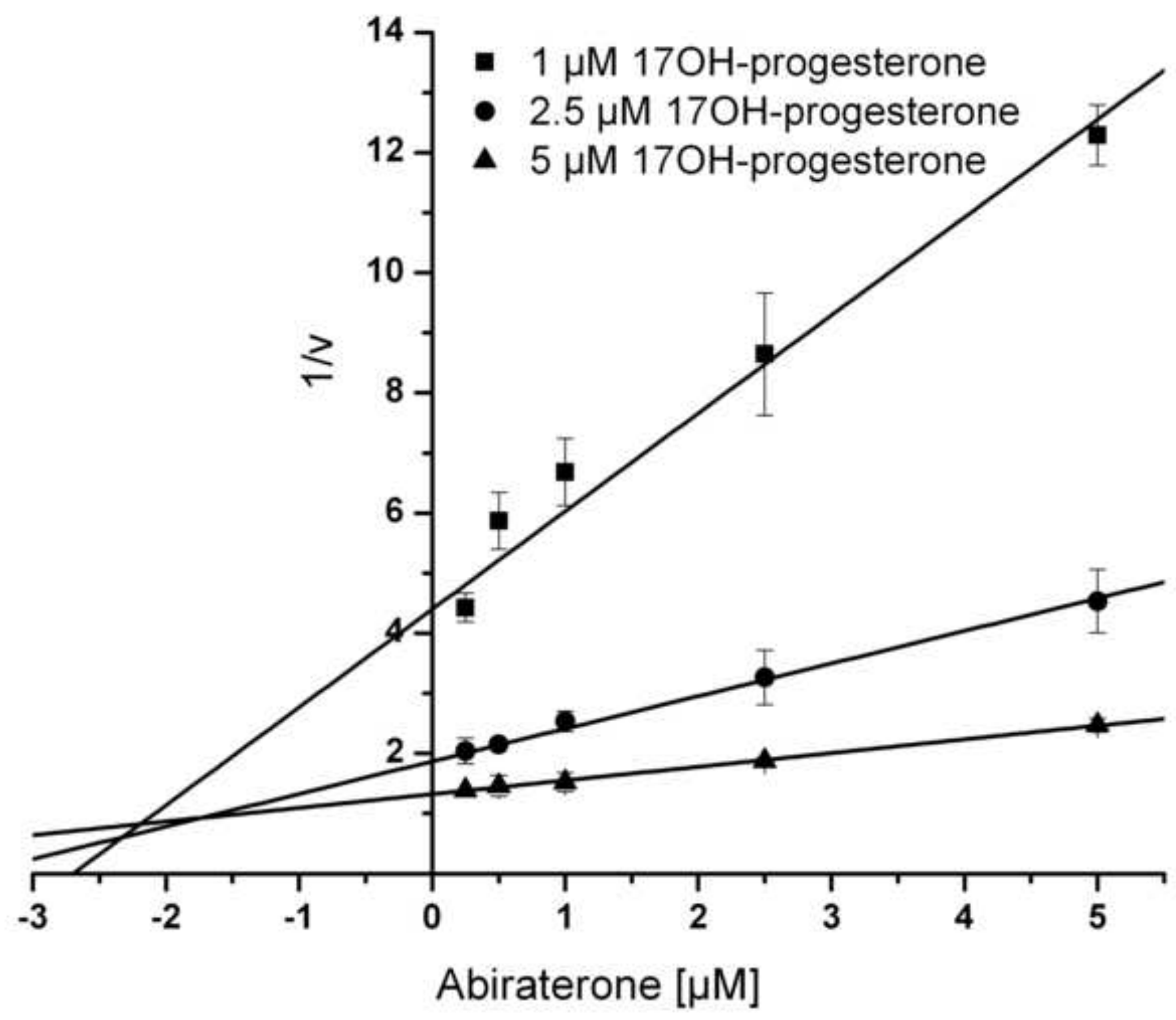




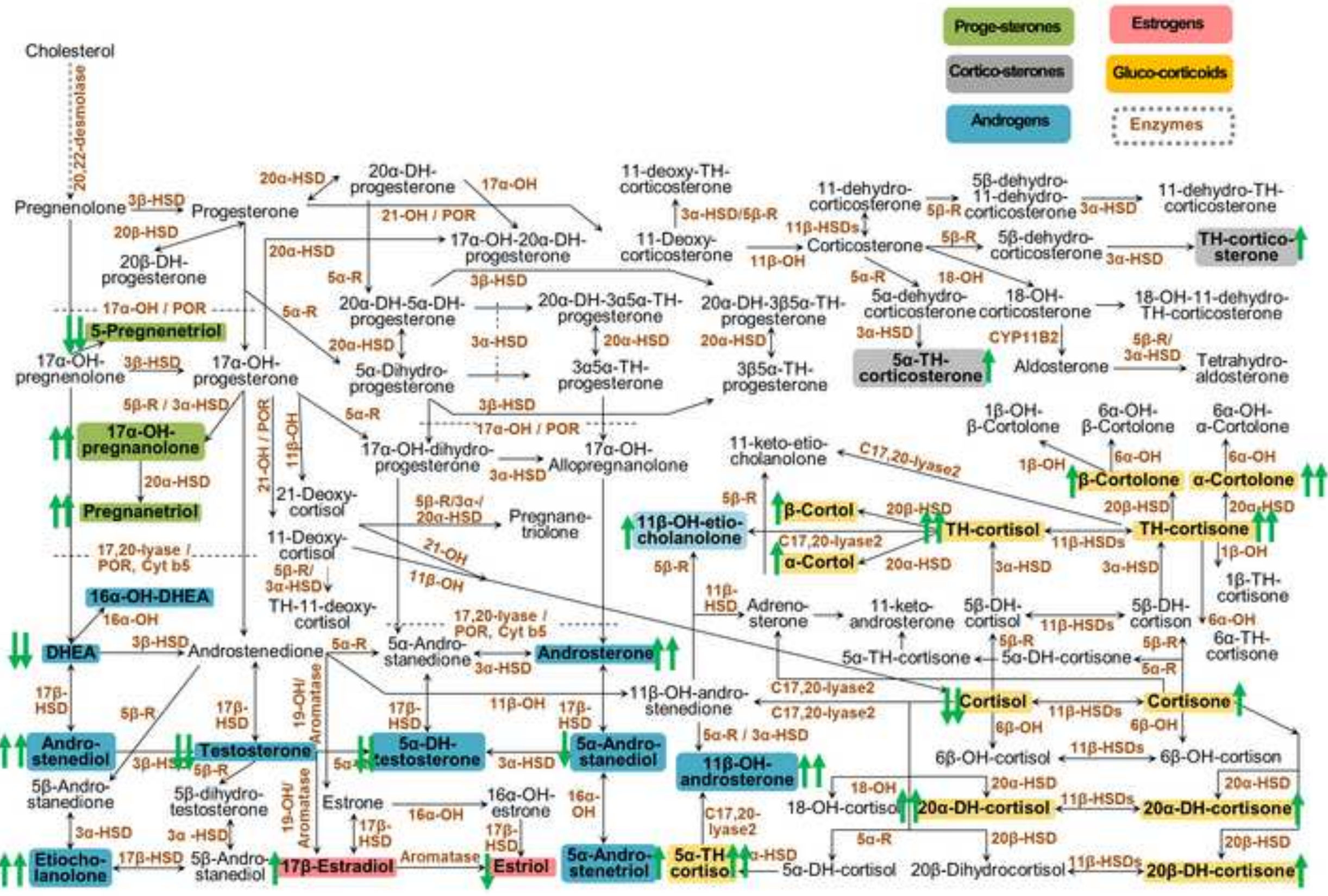

